\title{
How to reduce excessive use of health care service in medical aid beneficiaries: an economic impact of community-based case management
}

Myung Ja Kim

Hwacheon County Office

Eunhee Lee ( $\nabla$ ehlee@hallym.ac.kr)

Hallym University https://orcid.org/0000-0002-4729-6692

Research article

Keywords: Case management, medical aid program, health care utilization, health care cost

Posted Date: July 10th, 2019

DOI: https://doi.org/10.21203/rs.2.11189/v1

License: (c) (i) This work is licensed under a Creative Commons Attribution 4.0 International License. Read Full License 


\section{Abstract}

Background Community based case management for medical aid beneficiaries was implemented in Korea to induce rational use of medical care among the beneficiaries and stabilize the financial system. This study investigated the economic impact of community based case management on health care utilization and cost. Methods This study is a quantitative policy evaluation study to evaluate the impact of case management on excessive use of health care service in medical aid beneficiaries using national database. Results Total 1,741 medical aid beneficiaries with case management included in this study. Case management was provided to three target group, high-risk, long-term inpatient, and intensive care group. An increase in health-related quality of life (QOL) and the ability to use appropriate health care and a reduction in health care utilization and cost were observed for case management. There was no significant difference in the reduction in the total number of visiting days and the cost between the groups. Conclusions An increase in the health care utilization among medical aid beneficiaries has been observed due to the aging population and increase in the number of recipients. To reduce health care costs while maintaining the health status of the beneficiaries, it is necessitated to expand the targeted management.

\section{Background}

The national whole population in Korea is covered by health care system namely, National Health Insurance (NHI) program or Medical Aid Program. Most of Koreans (96\%) are covered by the NHI program, while 3-4\% of people who are unable to pay for their own health care coverage are covered by Medical Aid Program [1,2]. Hence, Medical Aid Program is considered as one of the social security system, which covers medical services such as illness, injuries, and childbirth to prevent illness caused by poverty [3-5]. The Medical Aid Program is financed by both the central government and the local government and is classified as type 1 and type 2 based on the status of people as being incapable (those under 18 or over 65 years of age or disabled) or capable of working [2,6]. Type 1 has the criteria of no copayment for all the medical uses, while type 2 includes some deduction [6]. Even if the recipients are covered by Medical Aid Program, they are required to do some out-of-pocket payment; however, the amount is extremely lower compared to others covered by the NHI program [6].

Most of the recipients covered by the Medical Aid Program are underserved population such as elderly, disabled, or ill with a severely rare disease $[7,8]$. In addition, there is little or no copayment for medical aid. Health care expenditure for medical aid beneficiaries continues to increase by more than $30 \%$ a year [6]. Moreover, health care utilization for cases such as hospital visits is higher in medical aid beneficiaries than others covered by $\mathrm{NHI}[6,9]$. This circumstance might be partly attributable to the increase in the number of recipients and the increase in medical cost. Furthermore, the low perception of the medical cost of the recipients, and oversupply might lead to an increase in health care cost of medical aid $[7,9]$.

To induce rational use of medical care by beneficiaries and stabilize the financial system, community based case management for medical aid beneficiaries was started in 2003 in Korea [2,5]. Its demand has been increasing continuously due to the aging population and increase in the number of recipients. Community based case management was first initiated for the beneficiaries who use an excessive amount of outpatient services to reduce the utilization. Subsequently, it was implemented to manage long-term inpatient cases with an aim to manage hospitalization costs $[5,10]$. Lastly, case management for intensive care group was newly established to manage subjects who frequently use outpatient treatment and inpatient medical care [5]. Apparently, it is stated that case management for medical aid beneficiaries provides targeted services suitable for three groups, high-risk group, longterm inpatient group, and the intensive care group. 
Previous studies have analyzed the effectiveness of case management for medical aid beneficiaries [1,10-12]. Most of the reported studies focused on a specific group rather than the entire groups. Moreover, there exists no study to analyze the effectiveness of case management in all the groups and the difference in effectiveness with respect to individual groups. Therefore, this study aimed to analyze the effect of case management for medical aid beneficiaries based on the target groups to provide appropriate services for each group in the future.

\section{Methods}

This study is a quantitative program evaluation study to evaluate the effectiveness of community based case management on excessive use of health care service in medical aid beneficiaries.

\section{Sample and data source}

This study included medical beneficiaries who had enrolled in case management in 2016 . We only included the subjects who had enrolled and terminated to case management in 2016 and excluded the subjects who terminated early due to transfer or death. The case manager who is registered nurse or social worker provided an initial assessment of all the medical beneficiaries for the requirements of case management and divided them into three target groups as a high-risk group, long-term inpatient group, and intensive care group, according to the pattern of health care utilization. The high-risk group included subjects who used inadequate outpatient services, while longterm inpatient group included subjects who used frequent inpatient services. Intensive care group is targeted for the beneficiaries who demonstrate the extensive use of medical services for both inpatient and outpatient care. Amongst the medical beneficiaries with case management, approximately $60 \%, 25 \%$, and $15 \%$ belonged to the highrisk group, long-term inpatient group, and intensive care group, respectively. To prevent sampling error, we extracted the samples according to the entire proportion of three target groups. Moreover, as there exists a specific pattern of health care utilization based on the region in Korea such as urban and rural, this study employed stratified proportion sampling reflecting the specific region. Consequently, 1741 beneficiaries, consisting of 1107, 351, and 283 beneficiaries from the high-risk group, long-term inpatient group, and the intensive care group were included in the present study, respectively.

The data about health care utilization and health care expenditure are accumulated in the NHI database in Korea. In addition, case managers submit health assessment data to region database about beneficiaries who are enrolled for the case management. With appropriate permission, we used the database of 198 regions and received the beneficiaries' data. Subsequently, we built the analytic dataset by assembling assessment data and health care utilization, and expenditure data extracted from the $\mathrm{NHI}$ database.

\section{Variables}

The data collected from the database of 198 regions included general characteristics of medical aid beneficiaries, service performances of case managers, and assessment data. In addition, the data extracted from the NHI database included health care cost and utilization.

General characteristics were gender, age, medical aid type, re-enrollment, residence status, presence of housemate, education level, region, and main disease. Case managers provided the service by home visit, phone, mail, hospital visit, transitional care such as resource liaison among hospital, other facilities, and home, referral to hospital. We calculated the total amount of services and frequency of each method per person. 
Primary outcome of case management was the change in health-related quality of life (QOL), and perceptions about health care utilization. We evaluated the primary outcome using assessment data, which included health-related QOL, personal power of health care, rational use of health service, and supporting system. As an intensive care group was categorized most recently, other groups were not expected to have the same assessment data. Healthrelated QOL was measured by different instruments by the groups, short form-36 (SF-36) for the high-risk group and long-term inpatient group and Euro-quality of life-5 dimension (EQ-5D) for intensive care group. In addition, other assessment indicators except health-related QOL were only investigated in the high-risk group and long-term inpatient group.

Secondary outcome was defined as changes in actual health care utilization and cost. Health care utilization refers to the number of days of hospitalization, both inpatient and outpatient. Health care cost includes all costs associated with health care such as treatment cost, hospitalization cost, and drug costs. We extracted the data of health care utilization and cost for the year (2015) before the initiation of case management and for the year (2016) after the service.

\section{Analysis}

To summarize the data, general characteristics of medical aid beneficiaries with case management were reported as the mean and standard deviation for continuous variables and frequencies and percentages for categorical variables. We used a Chi-square test and ANOVA to find out whether general characteristics significantly differed based on the target groups. Service performance reported the total frequencies and the average number of service per person. Changes in assessment data and health care utilization, and cost between before and after targeted management were analyzed by paired t-test. Lastly, the difference in health care utilization and cost among target groups was analyzed by ANCOVA by adjusting the variable which showed differences based on the groups. The collected data were analyzed using SPSS WIN 22.0 and Stata SE version 14.

\section{Results}

\section{Difference in general characteristics of the target groups for case management}

Table 1 shows the general characteristics of medical aid beneficiaries who were provided case management and differences in general characteristics of the target groups. The target group for case management was divided into three groups, high-risk group, long-term inpatient group, and intensive care group. Among 1,741 medical aid beneficiaries, who were provided with case management, 1,107 beneficiaries were present in the high-risk group, followed by long-term inpatient group (351 beneficiaries) and intensive care group (283 beneficiaries). Overall, 1,083 beneficiaries were women (62.2\%). The high-risk group and the intensive care group had more than $60 \%$ of women, while, in the long-term admission group, the proportion of women was lower than other groups $\left(\operatorname{chi}^{2}=25.039, p=\right.$ .000). The average age of the beneficiaries was 69.5 years and the proportion of individuals over 65 years was significantly higher in the high-risk group $\left(70.8 \%\right.$, chi $\left.^{2}=12.950, p=.002\right)$. Approximately $95 \%$ of medical aid beneficiaries enrolled for case management was of type 1, and a similar pattern was observed in all the groups. Typically, $72.1 \%$ of beneficiaries received the case management more than twice. There were differences between the groups: $76.1 \%$ in the high-risk group, $61.5 \%$ in the long-term admitted group, and $70 \%$ in the intensive care group $\left(\mathrm{chi}^{2}=28,766, p=<.001\right)$. There were $1,065(61.2 \%)$ cases without housemate. Based on the targeted groups, it was noted that the proportion of living alone was highest in the long-term inpatient group, followed by intensive care group and high-risk group. There were statistically significant differences between the groups $\left(\right.$ chi $\left.^{2}=27,653, p<.001\right)$, also with respect to education level and region. More than $60 \%$ of beneficiaries lived in small cities or rural areas 
and approximately $70 \%$ of beneficiaries had an education level of elementary school or less. The most frequent disease was circulatory diseases, which showed a similar distribution in the high-risk group and intensive care group. The proportion of mental disorder such as dementia accounted for $10-20 \%$ in both the high-risk group and intensive care group, whereas it was above $30 \%$ in the long-term inpatient group.

\section{Service duration and performance of case management by target groups}

Service duration and performance status of case management are demonstrated in Table 2. As per the target groups, the duration of service provided was up to 12 months in the case of intensive care group, which was longer compared to other groups. The high-risk group was provided the service for a short duration of 3 months; however, were provided with a large amount of service per month. An average number of service per person in intensive care group was 16.20 times, which was highest compared to other groups. However, as they were provided the service for 12 months, the monthly average was not the highest.

The service for case management was delivered by telephone, mail, home visit, transitional care (resource liaison), hospital visit, and referral to hospital. The service method showed a similar distribution in all the target groups. The phone call was the most commonly used service among entire services for every group, followed by mail, home visit, and transitional care. The frequency of hospital visit and referral to other institutions was low in all the groups. Considering that the service duration was different for the target group, the high-risk group received enormous service within a short period of time.

\section{Changes in service outcomes for case management: primary and secondary}

Health-related QOL before enrollment of case management in the high-risk group was 17.20, which was lower than that in long-term inpatient group (18.53) (Table 3). After providing case management, the health-related QOL was significantly improved in all the groups. Compared to the long-term inpatient group, the health-related QOL was significantly improved in the high-risk group $(t=29.290, p<.001)$. In terms of the personal power of health care, the pre-score in long-term inpatient group (12.64) was lower than that in the high-risk group (15.41). Moreover, the score in long-term inpatient group exhibited a low increase than in high-risk group. Rational utilization of health service showed a statistically significant change in both the groups for case management, which was increased from 14.08 to 18.37 in the high-risk group $(t=41.019, p<.001)$ and from 17.75 to $17.95(t=11.196, p<.001)$ in the long term inpatient group. The supporting system increased significantly from 5.85 to $6.43(t=17.054, p<.001)$ in the high-risk group and from 6.32 to 6.99 in the long-term administration group $(t=9.842, p<.001)$.

Before enrollment for case management, total visiting days during a year in long-term inpatient group was 287.2 days, which was highest among all the groups, followed by intensive care group (218.2 days) and high-risk group (158.3 days). The inpatient days in a year was estimated as 240.2 days in long-term inpatient group, which was overwhelmingly high compared to other groups. The outpatient days in a year were relatively high in the high risk group (128.3 days) and the intensive care group (182.6 days), compared to long-term inpatient group (47.3 days). Both the inpatient and outpatient days showed a statistically significant decrease due to case management. Before enrollment for case management, total health care expenditure in a year was highest in the long-term inpatient group and the expenditure was same in both the intensive care group and the high-risk group. After case management, a significant decrease was observed in not only the number of visiting days but also in the health care expenditure in all the groups (Figure 1). 
Differences in health care utilization and health care cost by the groups were analyzed by adjusting the variables and the difference was observed to be statistically significant (Table 4). Total visiting days per person drastically reduced by 60.5 days in intensive care group, followed by 47.2 days and 43.2 days in long-term inpatient group and high-risk group, respectively. However, there was no statistically significant difference in change in the total number of visiting days by the groups. Unlike total visiting days, utilization by inpatient and outpatient exhibited a significant difference among target groups. Inpatient days were mainly reduced in the long-term inpatient group, while outpatient days were reduced mainly in the intensive care group. A great reduction in health care expenditure per person was observed in a high risk group (USD 4007.9) followed by long-term inpatient group (USD 3592.6) and intensive care group (USD 3197.0). However, there was no significant difference between the different groups.

\section{Discussions}

Among the beneficiaries enrolled for community based case management, the proportion of women was higher than men and there were more elderly people (under 64 years). As the medical aid program in Korea is targeted for a vulnerable group, the proportion of elderly is expected to be higher as beneficiaries enrolled for case management. In Medicaid type, most of the subjects were covered by type 1 medical aid program, which could be attributed to the fact that type 1 medical aid recipients have little out-of-pocket payment. Previous studies reported that the more the patients are covered by the insurance, the more they use medical services $[2,4,8,12]$. Hence, insurance type or insurance coverage affects health care utilization. Therefore, as medical aid beneficiaries, both type 1 and type 2 are likely to use health care services frequently due to wide coverage; they might be a target of case management. The majority of them had an education level of elementary school or less only, which is consistent with other studies $[1,14]$. Health are deeply influenced by several social factors, and one of the factors is education. Hence, the education level is related to health literacy, and it contributes to an individual's health [15]. Most of the beneficiaries who had enrolled for case management might be vulnerable to diseases due to low literacy level, hence it is needed to improve health literacy through case management. The long-term hospitalization group showed a significantly lower rate (26.8\%) of housemate compared to the other groups (39.6-42.5\%), which is consistent with another study $[1,7,12]$. Beneficiaries without housemate are not provided caring service at home if they come down with the disease. Therefore, they have the option to totally rely on inpatient care, in case they are unable to take appropriate care by outpatient. Re-enrollment rate (72.1\%) was significantly higher than the initial enrollment in all the groups, demonstrating significant differences among the subject groups $\left(\chi^{2}=28.766, p<.000\right)$. High rate of re-enrollment could be attributed to the reality that most of the beneficiaries still need a large amount of medical services due to disease, or due to the increase in the medical use again after the termination of service. Hence, it could be interpreted that the sustainability effect of case management is declining with time. In addition, service duration might affect re-enrollment. High-risk group were provided with services for 3 months, which was the shortest and the re-enrollment rate was highest in the group compared to other groups. In addition, not only high-risk group but also other groups provided during quite short time compared to other study [12]. As most of the subjects for case management have several diseases, and they depend on medical care and drugs, pattern of medical use is difficult to change in a short time. Therefore, providing sufficient time for managing the target group seems essential. Thus, based on the investigations of the reasons of re-enrollment, it is needed to evaluate monthly health care utilization subsequent to termination of case management. Furthermore, additional review of the service provision period is needed.

All primary outcomes such as health-related QOL, personal power of health care, rational medical utilization, and support system were found to be effectively improved, and the results are consistent with the results of previous studies [14,16-18]. However, it was difficult to compare all the indicators related to program outcome, because 
health-related QOL was measured by different instruments by groups, and other indicators were not investigated in the intensive care group. For comparing the effect of case management by groups, it is necessary to develop common indicators for evaluating the program outcome.

Not only primary outcomes but also secondary outcome such as health care utilization and cost decreased significantly in all the groups due to case management, which is consistent with the outcomes of several studies $[2,6,11,12]$. Major reduction in total visiting days among the groups was in intensive care group, followed by longterm inpatient group, and high-risk group; however, no significant difference was observed among the groups by adjusting the covariates. Intensive care group was provided service for the longest period. Considering the period, the effectiveness of case management in the intensive care group was probably not greater compared to other groups. However, by examining each part of health utilization, long-term inpatient group showed the greatest effectiveness in inpatient days, and intensive care group showed the greatest impact in outpatient days. This result contributes to the presence of difference in the type of medical use behavior and some characteristics among the groups.

Health care cost decreased significantly in all the groups after case management; however, by adjusting the covariates, no significant difference in the reduction was observed among the groups. Despite the difference in the period of time with respect to service, health care utilization and cost were not significantly different between the groups. In term of efficiency, case management showed the best performance in the high-risk group. It was difficult to induce a change in behavior in the intensive care group in a short period of time compared to the high-risk group. Hence, in the case of management, it is important to distinguish between target groups and provide service according to the characteristics of the group.

This study has some limitations. We could not evaluate the effectiveness of case management on the same outcome indicator for all groups due to a lack of outcome variable in the database. Also, we could not evaluate the objective health outcome because of data access restrictions.

\section{Conclusions}

This study investigated the economic impact of case management on health care utilization and cost. Healthrelated QOL and the ability to use appropriate health care were increased significantly after case management, and health care utilization and cost were found to be significantly reduced after case management. Despite the different characteristics of each group, the reduction in health care utilization and cost were similarly induced through targeted management.

\section{Abbreviation}

QOL: Quality of life; NHIL: National health insurance; SF-36: short form-3; EQ-5D: Euro-quality of life-5 dimension; USD: United States dollar

\section{Declarations}

Ethics approval and consent to participate

This study been approved by the Ethics Committee of Hallym University (No. 2017-06-29).

As this study used database from NHI, we did not need to take consent to each participants. 
Consent of publication

Not applicable

Availability of data and materials

The datasets used and/or analyzed during the current study are available from the corresponding author on reasonable request.

Competing interests

The authors are solely responsible for the content and writing of the patient. The authors report no conflicts of interest.

Funding

This work was supported by Hallym University (HRF-201904-011).

Authors' contributions

EL particularly contributed to the study aim, research design and overall structure of the manuscript. MK and EL conducted all the statistical analyses and drafted the manuscript.

Acknowledgements

The authors would like to acknowledge case manager in Korea for providing data, and Hallym university for financial support.

\section{References}

1. Ahn YH, Kim ES, Ham OK, Kim SH, Hwang SS, Chun SH, et al. Factors associated with the overuse or underuse of health care services among medical aid beneficiaries in Korea. J Community Health Nurs. 2011;28:190-203.

2. Kim J, Shon C. The effects of health coverage schemes on length of stay and preventable hospitalization in Seoul. Int J Environ Res Public Health. 2018;15.

3. Cho HW, Chu C. The story of Korean health insurance system. Osong Public Health Res Perspect. 2017;8:235-6.

4. Fry CE, Sommers BD. Effect of Medicaid expansion on health insurance coverage and access to care among adults with depression. Psychiatr Serv. 2018;69:1146-52.

5. Shin HW, Yeo NG. Current state and challenges of Medical Aid Programme. Health and Welfare Policy Forum. 2016;241:32-42.

6. Kim JH, Lee KS, Yoo KB, Park EC. The differences in health care utilization between Medical Aid and health insurance: a longitudinal study using propensity score matching. PLoS One. 2015;10:e0119939.

7. Shin SM, Kim MJ, Kim ES, Lee HW, Park CG, Kim HK. Medical Aid service overuse assessed by case managers in Korea. J Adv Nurs. 2010;66:2257-65. 
8. Sommers BD, Blendon RJ, Orav EJ, Epstein AM. Changes in utilization and health among low-income adults after Medicaid expansion or expanded private insurance. JAMA Intern Med. 2016;176:1501-09.

9. Kim JH, Lee SG, Lee KS, Jang SI, Cho KH, Park EC. Impact of health insurance status changes on healthcare utilisation patterns: a longitudinal cohort study in South Korea. BMJ Open. 2016;6:e0095.

10. Oh J, Oh S. Nurse case managers' experiences on case management for long-term hospitalization in Korea. Asian Nurs Res. 2017;11:283-9.

11. Bodenmann P, Velonaki VS, Griffin JL, Baggio S, Iglesias K, Moschetti K, et al. Case management may reduce emergency department frequent use in a universal health coverage system: a randomized controlled trial. J Gen Intern Med. 2017;32:508-15.

12. Joo JY, Liu MF. Case management effectiveness in reducing hospital use: a systematic review. Int Nurs Rev. 2017;64:296-308.

13. Pickens G, Karaca Z, Cutler E, Dworsky M, Eibner C, Moore B, et al. Changes in hospital inpatient utilization following health care reform. Health Serv Res. 2018;53:2446-69.

14. Shin HS, Oh JJ. Case management for medical aid beneficiaries in Korea: findings from case-control study. Asian Nurs Res. 2014;8:274-81.

15. van der Heide I, Wang J, Droomers M, Spreeuwenberg P, Rademakers J, Uiters E. The relationship between health, education, and health literacy: results from the Dutch Adult Literacy and Life Skills Survey. J Health Commun. 2013;18:172-84.

16. Hammer BJ. Community-based case management for positive outcomes. Geriatr Nurs. 2001;22:271-5.

17. Corvol A, Dreier A, Prudhomm J, Thyrian JR, Hoffmann W, Somme D. Consequences of clinical case management for caregivers: a systematic review. Int J Geriatr Psychiatry. 2017;32:473-83.

18. Weintraub WS, Elliott D, Fanari Z, Ostertag-Stretch J, Muther A, Lynahan M, et al. The impact of care management information technology model on quality of care after coronary artery bypass surgery: "Bridging the Divides". Cardiovasc Revasc Med. 2018;19:106-11.

\section{Tables}


Table 1. General characteristics of medical aid beneficiaries enrolled in community based case management

\begin{tabular}{|c|c|c|c|c|c|c|c|}
\hline \multirow[t]{2}{*}{ Variables } & \multirow[t]{2}{*}{ Categories } & \multirow{2}{*}{$\begin{array}{c}\text { Total } \\
(\mathrm{n}=1,741)\end{array}$} & \multicolumn{3}{|c|}{ Group } & \multirow[t]{2}{*}{ F/chi2 } & \multirow[t]{2}{*}{$p$-value } \\
\hline & & & $\begin{array}{c}\text { High } \\
\text { risk } \\
(n=1,107)\end{array}$ & $\begin{array}{c}\text { Long- } \\
\text { term } \\
\text { inpatient } \\
(n=351)\end{array}$ & $\begin{array}{c}\text { Intensive } \\
\text { care } \\
(n=283)\end{array}$ & & \\
\hline \multirow[t]{2}{*}{ Gender } & Women & $1,083(62.2)$ & $729(65.9)$ & $179(51.0)$ & 175(61.8) & 25.039 & $<.001$ \\
\hline & Men & 658(37.8) & $378(34.1)$ & $172(49.0)$ & 108(38.2) & & \\
\hline \multirow[t]{3}{*}{ Age } & All & $69.5 \pm 12.1$ & $70.2 \pm 11.2$ & $68.9 \pm 14.3$ & $67.8 \pm 12.3$ & 5.045 & .007 \\
\hline & Under 64 years & $561(32.2)$ & $323(29.2)$ & 133(37.9) & 105(37.1) & 12.950 & .002 \\
\hline & Over 65 years & $1,180(67.8)$ & $784(70.8)$ & $218(62.1)$ & $179(62.9)$ & & \\
\hline \multirow{2}{*}{$\begin{array}{l}\text { Medical } \\
\text { care type }\end{array}$} & Type1 & $1,667(95.7)$ & $1,052(95.0)$ & $343(97.7)$ & $272(96.1)$ & 4.845 & .089 \\
\hline & Туре2 & $74(4.3)$ & $55(5.0)$ & $8(2.3)$ & $11(3.9)$ & & \\
\hline \multirow[t]{2}{*}{ Enrollment } & Re-enroll & $1,256(72.1)$ & $842(76.1)$ & $216(61.5)$ & 198(70.0) & 28.766 & $<.001$ \\
\hline & First enroll & $485(27.9)$ & $265(23.9)$ & $135(28.5)$ & $85(30.0)$ & & \\
\hline \multirow[t]{2}{*}{ Housemate } & No & $1,065(61.2)$ & $637(57.5)$ & $257(73.2)$ & $171(60.4)$ & 27.653 & $<.001$ \\
\hline & Yes & 676(38.2) & $470(42.5)$ & $94(26.8)$ & $112(39.6)$ & & \\
\hline \multirow[t]{4}{*}{ Education } & Pre-primary & $730(41.9)$ & $485(43.9)$ & $135(38.5)$ & $110(28.9)$ & 5.530 & .478 \\
\hline & Primary & $488(28.0)$ & $305(27.6)$ & $99(28.2)$ & 84(29.7) & & \\
\hline & $\begin{array}{l}\text { Lower } \\
\text { secondary }\end{array}$ & 232(13.3) & 143(12.9) & $49(14.0)$ & $40(14.1)$ & & \\
\hline & $\begin{array}{l}\text { Upper } \\
\text { secondary }\end{array}$ & 291(16.7) & $174(15.7)$ & $68(19.4)$ & $49(17.3)$ & & \\
\hline \multirow[t]{3}{*}{ Region } & Metropolitan & $615(35.3)$ & $381(34.4)$ & $127(36.2)$ & 107(37.8) & 2.358 & .670 \\
\hline & $\begin{array}{l}\text { Non- } \\
\text { metropolitan }\end{array}$ & $594(34.1)$ & 375(33.9) & $121(34.5)$ & $98(34.6)$ & & \\
\hline & Rural & $532(30.6)$ & $351(31.7)$ & $103(29.3)$ & $78(27.6)$ & & \\
\hline \multirow{6}{*}{$\begin{array}{l}\text { Main } \\
\text { disease }\end{array}$} & Cardiovascular & $586(33.7)$ & $394(35.6)$ & $107(30.5)$ & $85(30.0)$ & 121.952 & $<.001$ \\
\hline & Musculoskeletal & $316(18.2)$ & 209(18.9) & $35(10)$ & $72(25.4)$ & & \\
\hline & Mental disorder & 289(16.6) & $137(12.4)$ & $113(32.2)$ & $39(13.8)$ & & \\
\hline & $\begin{array}{l}\text { Endocrine } \\
\text { disease }\end{array}$ & $246(14.1)$ & 183(16.5) & $21(6.0)$ & $42(14.8)$ & & \\
\hline & Neoplasm & 186(10.7) & $104(9.4)$ & $55(15.7)$ & $27(9.5)$ & & \\
\hline & Others & 118(6.8) & $80(7.2)$ & $20(5.7)$ & $18(6.4)$ & & \\
\hline
\end{tabular}


Table2. Service duration and performance of community based case management by targeted groups

\begin{tabular}{|c|c|c|c|c|}
\hline & & $\begin{array}{l}\text { High } \\
\text { risk }\end{array}$ & $\begin{array}{l}\text { Long-term } \\
\text { Inpatient }\end{array}$ & $\begin{array}{l}\text { Intensive } \\
\text { care }\end{array}$ \\
\hline & & $(n=1,107)$ & $(n=351)$ & $(n=283)$ \\
\hline Duration (months) & & 3 & 5 & within 12 \\
\hline \multirow[t]{7}{*}{ Frequency of service, n(\%) } & Total & 9,814 & 3,651 & 4,584 \\
\hline & Phone & $4,814(49.1)$ & $1,946(53.3)$ & $2,292(50.0)$ \\
\hline & Mail & $2,503(25.5)$ & $784(21.5)$ & $1,078(23.5)$ \\
\hline & Home visit & $2,278(23.2)$ & $783(21.4)$ & $945(20.6)$ \\
\hline & Transitional care & $160(1.6)$ & $115(3.1)$ & $176(3.8)$ \\
\hline & Hospital visit & $50(0.5)$ & $3(0.1)$ & $82(1.8)$ \\
\hline & $\begin{array}{l}\text { Referral to } \\
\text { hospital }\end{array}$ & $9(0.1)$ & $20(0.5)$ & $11(0.2)$ \\
\hline \multirow{7}{*}{$\begin{array}{c}\text { Number of service per person, } \\
\text { mean } \pm \text { SD }\end{array}$} & Total & $8.87 \pm 1.54$ & $10.40 \pm 4.10$ & $16.20 \pm 6.00$ \\
\hline & Phone & $4.35 \pm 0.78$ & $5.54 \pm 2.58$ & $8.10 \pm 3.27$ \\
\hline & Mail & $2.26 \pm 1.02$ & $2.23 \pm 1.42$ & $3.81 \pm 2.53$ \\
\hline & Home visit & $2.06 \pm 0.36$ & $2.23 \pm 1.11$ & $3.34 \pm 1.49$ \\
\hline & Transitional care & $0.14 \pm 0.43$ & $0.33 \pm 0.61$ & $0.62 \pm 1.09$ \\
\hline & Hospital visit & $0.05 \pm 0.24$ & $0.01 \pm 0.10$ & $0.29 \pm 1.14$ \\
\hline & $\begin{array}{l}\text { Referral to } \\
\text { hospital }\end{array}$ & $0.01 \pm 0.10$ & $0.06 \pm 0.23$ & $0.04 \pm 0.21$ \\
\hline
\end{tabular}


Table 3. Service outcome of community based case management by the targeted group

\begin{tabular}{|c|c|c|c|c|c|}
\hline \multirow[t]{2}{*}{ Variables } & \multirow[t]{2}{*}{ Group } & Before & After & \multirow[t]{2}{*}{ t } & \multirow{2}{*}{$\begin{array}{c}\text { p- } \\
\text { value }\end{array}$} \\
\hline & & (Mean \pm SD) & (Mean \pm SD) & & \\
\hline \multicolumn{6}{|l|}{ Primary outcome } \\
\hline \multirow[t]{3}{*}{ Health related QOL } & High risk & $17.20 \pm 2.98$ & $19.33 \pm 2.38$ & 29.29 & $<.001$ \\
\hline & $\begin{array}{l}\text { Long-term } \\
\text { inpatient }\end{array}$ & $18.53 \pm 4.00$ & $19.45 \pm 4.14$ & 8.675 & $<.001$ \\
\hline & Intensive care* & $0.68 \pm 0.14$ & $0.78 \pm 0.13$ & 11.912 & $<.001$ \\
\hline \multirow{2}{*}{$\begin{array}{l}\text { Personal power of health } \\
\text { care }\end{array}$} & High risk & $15.41 \pm 2.82$ & $18.64 \pm 2.52$ & 37.152 & $<.001$ \\
\hline & $\begin{array}{l}\text { Long-term } \\
\text { inpatient }\end{array}$ & $12.64 \pm 4.12$ & $14.05 \pm 4.49$ & 10.507 & $<.001$ \\
\hline \multirow[t]{2}{*}{ Rational use of health service } & High risk & $14.08 \pm 2.96$ & $18.37 \pm 3.35$ & 41.019 & $<.001$ \\
\hline & $\begin{array}{l}\text { Long-term } \\
\text { inpatient }\end{array}$ & $14.59 \pm 4.13$ & $17.95 \pm 5.69$ & 11.196 & $<.001$ \\
\hline \multirow[t]{2}{*}{ Supporting system } & High risk & $5.85 \pm 1.70$ & $6.43 \pm 1.45$ & 17.054 & $<.001$ \\
\hline & $\begin{array}{l}\text { Long-term } \\
\text { inpatient }\end{array}$ & $6.32 \pm 1.73$ & $6.99 \pm 1.65$ & 9.842 & $<.001$ \\
\hline \multicolumn{6}{|l|}{ Secondary outcome } \\
\hline \multirow[t]{3}{*}{ Visiting days } & High risk & $158.3 \pm 129.2$ & $115.1 \pm 116.5$ & 14.717 & $<.001$ \\
\hline & $\begin{array}{l}\text { Long-term } \\
\text { inpatient }\end{array}$ & $287.2 \pm 129.7$ & $240.0 \pm 109.6$ & 5.969 & $<.001$ \\
\hline & Intensive care & $218.2 \pm 138.5$ & $157.7 \pm 125.4$ & 12.019 & $<.001$ \\
\hline \multirow[t]{3}{*}{ Inpatient } & High risk & $30.5 \pm 23.0$ & $10.6 \pm 30.7$ & 17.766 & $<.001$ \\
\hline & $\begin{array}{l}\text { Long-term } \\
\text { inpatient }\end{array}$ & $240.2 \pm 141.3$ & $206.0 \pm 117.6$ & 3.924 & $<.001$ \\
\hline & Intensive care & $36.1 \pm 64.1$ & $18.7 \pm 49.2$ & 5.898 & $<.001$ \\
\hline \multirow[t]{3}{*}{ Outpatient } & High risk & $128.3 \pm 120.4$ & $104.7 \pm 111.1$ & 8.716 & $<.001$ \\
\hline & $\begin{array}{l}\text { Long-term } \\
\text { inpatient }\end{array}$ & $47.3 \pm 93.9$ & $34.5 \pm 56.1$ & 2.540 & .012 \\
\hline & Intensive care & $182.6 \pm 137.1$ & $138.9 \pm 119.6$ & 9.821 & $<.001$ \\
\hline
\end{tabular}

Note: Distribution of health-related QOL for the intensive care group was different from other groups because the instrument of health-related QOL for the intensive care group was different. 
Table 4. Comparison of changes in health care utilization and cost in the targeted group

\begin{tabular}{lcccccc}
\hline & High risk $^{\mathbf{a}}$ & Long-term inpatient $^{\mathbf{b}}$ & Intensive care $^{\mathbf{c}}$ & $\mathbf{F}$ & p-value & Post-hoc \\
\cline { 2 - 4 } & $(\mathrm{n}=1107)$ & $(\mathrm{n}=351)$ & $(\mathrm{n}=283)$ & & & \\
\hline Visiting days & $43.2 \pm 37.2$ & $47.2 \pm 148.8$ & $60.5 \pm 83.9$ & 2.88 & .057 & \\
\hline Inpatient & $19.9 \pm 44.6$ & $34.3 \pm 163.3$ & $17.4 \pm 49.2$ & 4.45 & .012 & $\mathrm{~b}>\mathrm{a}, \mathrm{b}>\mathrm{c}$ \\
\hline Outpatient & $23.3 \pm 90.2$ & $12.9 \pm 93.9$ & $43.1 \pm 74.5$ & 9.73 & .000 & $\mathrm{c}>\mathrm{a}, \mathrm{c}>\mathrm{b}$, \\
\hline Health care cost, $\mathbf{\$}$ & $4007.9 \pm 6519.6$ & $3592.6 \pm 11002.9$ & $3197.0 \pm 5621.9$ & 1.46 & .233 & \\
\hline
\end{tabular}

\section{Figures}

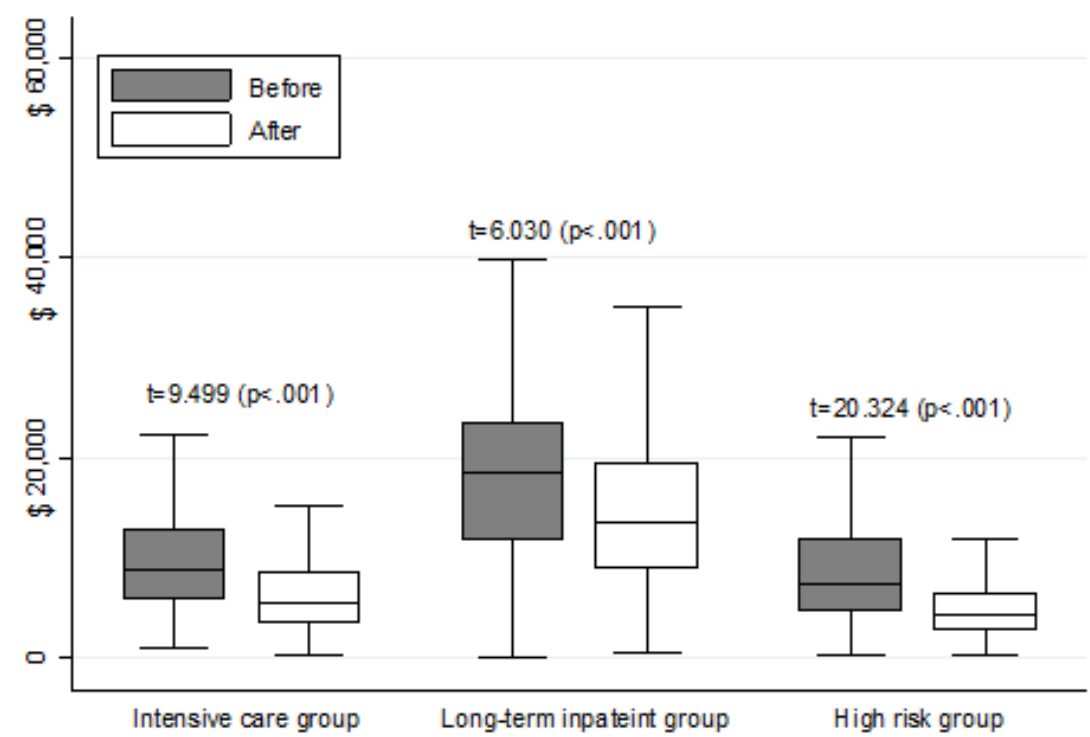

Figure 1

Changes in health care cost in the targeted group. 